BMJ

Open

Gastroenterology

\title{
Use of hospital resources in the Finnish colorectal cancer screening programme: a randomised health services study
}

\author{
Suvi Mäklin, ${ }^{1}$ Matti Hakama, ${ }^{1}$ Pekka Rissanen, ${ }^{2}$ Nea Malila ${ }^{1,2}$
}

To cite: Mäklin S, Hakama M, Rissanen $\mathrm{P}$, et al. Use of hospital resources in the Finnish colorectal cancer screening programme: a randomised health services study. BMJ Open Gastro 2015;2:e000063. doi:10.1136/bmjgast-2015000063

Received 15 September 2015 Revised 5 November 2015 Accepted 23 November 2015
${ }^{1}$ Finnish Cancer Registry, Helsinki, Finland ${ }^{2}$ School of Health Sciences, University of Tampere, Tampere, Finland

Correspondence to Suvi Mäklin; Suvi.maklin@cancer.fi

\section{ABSTRACT}

Objective: To estimate the difference in use of hospital resources in the Finnish Colorectal Cancer (CRC) screening programme between those invited and controls, within the year of randomisation and the next year.

Design: CRC screening was implemented in Finland in 2004 as a population-based randomised design using biennial faecal occult blood test (FOBT) for men and women aged $60-69$ years. Those randomised to screening and control groups during years 2004-2009 were included in this analysis and use of hospital resources was estimated. Data were collected from the national register on hospital discharges. Outpatient visits, inpatient episodes and colonoscopies were compared between the two groups.

Results: The screening group comprised of 123149 and control group of 122930 people. Most people in both groups had not used hospital resources at all. More people in the screening group than in the control group had at least one hospital-based outpatient visit (7.8\% vs $7.4 \%)$, inpatient episode (3.9\% vs $3.8 \%$ ) and colonoscopy (1.5\% vs $1.3 \%)$. In total, the screening group had 31975 and control group 27061 cumulative outpatient visits, 9260 and 7903 inpatient episodes, and 2686 and 1756 hospital colonoscopies, respectively. The proportion of those with a positive FOBT result with at least one outpatient visit, one inpatient episode or one colonoscopy, was 3.7 times, 2.5 times or 9 times that of those with a negative FOBT result, respectively.

Conclusions: CRC screening using the FOBT slightly increased the volume of hospital outpatient visits, inpatient episodes and hospital colonoscopies in Finland.

\section{INTRODUCTION}

Colorectal cancer is the third most common cancer, following breast and prostate cancers, and the second most common cause of cancer deaths after lung cancer, in Europe, including in Finland. Within the 27 Member states of the European Union, 340000 people were diagnosed with colorectal cancer in 2012 and about 150000 people

\section{Summary box}

What is already known about this subject?

- According to randomised trials, Colorectal Cancer (CRC) screening with the guaiac-based faecal occult blood test (FOBT) reduces CRC-related mortality.

- Based on the available evidence, the EU recommends CRC screening.

- Evidence on the impact of guaiac-based FOBT screening on resource use is missing.

What are the new findings?

- Our study showed a slight increase in the use of hospital services (outpatient visits, inpatient episodes and colonoscopies) in the screening group compared to the control group.

- People who were invited to screening but who did not attend were more likely to use hospital resources for gastrointestinal reasons than people with a negative FOBT result.

How might it impact on clinical practice in the foreseeable future?

- This study only evaluates the resource use on a hospital level and not the impact of screening on primary healthcare services.

died because of it. ${ }^{1}$ Among 5.4 million Finns, the corresponding figures are approximately 2500 people diagnosed with colorectal cancer and more than 1000 deaths every year. The incidence of colorectal cancer increased for decades while mortality was stable among men and decreased among women since the 1970 s. $^{23}$

Colorectal cancer screening aims to reduce the mortality of the disease by discovering the cancer at an early, asymptomatic stage, to enable more effective and less invasive treatment. Screening with a faecal occult blood test (FOBT) has been shown to reduce mortality from colorectal cancer in a number of randomised screening studies. ${ }^{4-7}$ In a Cochrane review, ${ }^{8}$ the combined results of these studies showed a $16 \%$ reduction in the relative risk of colorectal cancer mortality. 
Three of these studies ${ }^{4} 67$ used biennial screening and showed an average of $15 \%$ relative risk reduction in colorectal cancer mortality. The reduction in mortality was seen in all three trials even though there was large variation in the design, such as the age of the target population, screening intervals, attendance rate and length of follow-up. Also, the cost-effectiveness of colorectal cancer screening has been modelled in a number of studies, in various countries, using different screening tests and strategies. ${ }^{9-15}$ Based on the available evidence, the Council of the European Union already, in 2003, recommended the implementation of a populationbased screening programme for colorectal cancer to the EU Member States. ${ }^{16}$

In Finland, colorectal cancer screening started in 2004 as a population-based randomised study. The idea was to launch a new screening programme in such a way that it can be reliably evaluated. The target population of screening is men and women aged 60-69 years, based on the fact that the incidence of and mortality from colorectal cancer increase after 60 years of age. ${ }^{3}$ The municipalities responsible for providing health services in Finland can voluntarily join the programme, and the number of piloting municipalities has increased from 22 (of 444) in 2004 to 153 (of 336) in 2012. The target population in these municipalities was randomised at an individual level within municipality, birth year and in sex specific blocks, to screening and control groups. Owing to the gradual expansion of the programme as a randomised health services study, ${ }^{17}$ the effects of the ultimate national screening programme on the allocation of health care resources can be evaluated as a part of routine health service.

The aim of this article was to estimate the difference in the use of hospital resources between those invited and the controls in the Finnish colorectal cancer screening programme within the first screening round.

\section{MATERIALS AND METHODS}

When the Finnish colorectal cancer screening study was launched, a national screening centre was established in the city of Tampere, at the local cancer society, to deal with the invitations, responses and recommendations for referrals, and to analyse the faecal samples. FOBT kits (Hemoccult; Beckman Coulter, USA) are posted to those offered screening along with a letter of invitation to participate in the programme and advice on how to take the sample. The kits are also returned by post. If any traces of blood are found in the sample, the person is referred to a contact nurse in their home municipality, for further examinations. Diagnostic confirmation, treatment and follow-up of people who screened positive are conducted within the normal health services at the local level and are paid for mostly by the home municipality of the participant being screened. Those in the control arm are identified but not contacted. The control population receives routine health services available in Finland. ${ }^{18}$
All individuals $(\mathrm{n}=246079)$ who were randomised to the colorectal cancer screening $(n=123$ 149) or control $(\mathrm{n}=122$ 930) groups during years 2004-2009 were identified and their data on healthcare resource use were gathered from the Finnish Hospital Discharge Register (FHDR). The follow-up of each individual was from the beginning of the year of randomisation up to the end of the next calendar year (two full years). The study period was 2004-2010.

For those randomised during the years 2004-2009, healthcare utilisation data on all gastrointestinal-related hospital-based outpatient visits and inpatient episodes of care were gathered on the year of randomisation and the following year. The data were restricted by ICD-10 codes that were related to gastrointestinal symptoms: C15-C26; D12 and K00-K93. Colonoscopies performed during those visits and episodes in hospitals were also examined, including procedure codes UJF32, UJF34 and UJF45. Colonoscopies performed in primary healthcare (including the screening colonoscopies) are not included in the analysis for either the screening or the control group. See table 1 for the explanation of the codes used in this article.

The FHDR is one of the oldest individual level hospital discharge registers covering an entire country. The FHDR has total (legislative) coverage of all inpatient care provided at university, general and psychiatric hospitals or primary care health centres, as well as treatment in military and prison wards and private hospitals, since 1969. Each record contains data on several variables, such as personal identity number, age at admission, gender, hospital identifier code, admission and discharge dates, reason for admission (ICD-10 code since 1996), and diagnostic and treatment activities. The register includes data on clinical procedures from 1986 onwards and the current coding system for procedures has been in use since 2004. The data on hospital outpatient visits have been collected since 1998 with some limitations and they are considered to be comparable from 2006 onwards. The completeness and accuracy of the FHDR has been reviewed to be good. Data on outpatient services at the primary care level (general practitioner visits, etc) are available from 1994 onwards at aggregate level. ${ }^{19} 20$

The percentage of people in the target population who used hospital services and the cumulative number of outpatient visits, hospital inpatient episodes and hospital colonoscopies, were calculated. We compared those randomised to screening to those in the control group. The screening group was also divided according to uptake of screening and test result. The differences between the arms in distributions of the individual variables were tested for statistical significance by the $\chi^{2}$ test.

\section{RESULTS}

The study population included 246079 people, 123149 $(50 \%)$ in the screening group and 122930 in the 
Table 1 Explanation of the diagnose and procedure codes used in the article

\begin{tabular}{|c|c|c|}
\hline \multirow[t]{25}{*}{ ICD-10 codes } & $C 15-C 26$ & Malignant neoplasms of digestive organs \\
\hline & C15 & Malignant neoplasm of oesophagus \\
\hline & C16 & Malignant neoplasm of stomach \\
\hline & C17 & Malignant neoplasm of small intestine \\
\hline & C18 & Malignant neoplasm of colon \\
\hline & C19 & Malignant neoplasm of rectosigmoid junction \\
\hline & $\mathrm{C} 20$ & Malignant neoplasm of rectum \\
\hline & $\mathrm{C} 21$ & Malignant neoplasm of anus and anal canal \\
\hline & $\mathrm{C} 22$ & Malignant neoplasm of liver and intrahepatic bile ducts \\
\hline & $\mathrm{C} 23$ & Malignant neoplasm of gall bladder \\
\hline & $\mathrm{C} 24$ & Malignant neoplasm of other and unspecified parts of biliary tract \\
\hline & $\mathrm{C} 25$ & Malignant neoplasm of pancreas \\
\hline & $\mathrm{C} 26$ & Malignant neoplasm of other ill-defined digestive organs \\
\hline & $D 12$ & Benign neoplasm of colon, rectum, anus and anal canal \\
\hline & K00-K93 & Diseases of the digestive system \\
\hline & $\mathrm{K} 00-\mathrm{K} 14$ & Diseases of oral cavity, salivary glands and jaws \\
\hline & K20-K31 & Diseases of oesophagus, stomach and duodenum \\
\hline & K35-K38 & Diseases of appendix \\
\hline & $\mathrm{K} 40-\mathrm{K} 46$ & Hernia \\
\hline & K50-K52 & Non-infective enteritis and colitis \\
\hline & K55-K63 & Other diseases of intestines \\
\hline & K65-K67 & Diseases of peritoneum \\
\hline & K70-K77 & Diseases of liver \\
\hline & K80-K87 & Disorders of gallbladder, biliary tract and pancreas \\
\hline & K90-K93 & Other diseases of the digestive system \\
\hline \multirow[t]{3}{*}{ National procedure codes* } & UJF32 & Colonoscopy \\
\hline & UJF34 & Left colonoscopy \\
\hline & UJF45 & Flexible sigmoidoscopy with biopsy \\
\hline
\end{tabular}

*Based on the Nordic Classification of Surgical Procedures.

control group. Based on the randomised setting of the study, the groups were similar in demographic characteristics.

By 2009, the programme covered about $40 \%$ of the ultimate target population and $20 \%$ were invited to screening. The attendance rate within the first screening round was $68 \%$ during the years 2004-2009, with some variation by calendar year. During these years, 2944 individuals $(2.4 \%)$ had a positive FOBT (table 2 ).

The number and proportion of people who had at least one gastrointestinal-related hospital outpatient visit, inpatient episode or colonoscopy during the year of randomisation or the next year, is presented in table 3 . Most of the study population in both screening and control groups had not had any gastrointestinal-related hospital outpatient visits or inpatient episodes within the 2 years following randomisation. The proportion of people with at least one outpatient visit, inpatient episode or colonoscopy, was higher in the screening group than in the control group, for all the types of resource use evaluated. The difference between the groups was the largest in outpatient visits: there were 523

Table 2 Number and percentage of individuals in the Finnish Colorectal Cancer Screening programme by year of invitation, arm and screening test result

\begin{tabular}{|c|c|c|c|c|c|c|c|c|}
\hline \multirow[b]{3}{*}{ Year of invitation } & \multicolumn{6}{|c|}{ Screening } & \multirow{3}{*}{$\begin{array}{l}\text { Screening total } \\
\text { n }\end{array}$} & \multirow{3}{*}{$\begin{array}{l}\text { Control } \\
\text { n }\end{array}$} \\
\hline & \multicolumn{2}{|c|}{$\begin{array}{l}\text { Positive test } \\
\text { result }\end{array}$} & \multicolumn{2}{|c|}{$\begin{array}{l}\text { Negative test } \\
\text { result }\end{array}$} & \multicolumn{2}{|c|}{ Non-attender } & & \\
\hline & $\mathrm{n}$ & Per cent & $\mathbf{n}$ & Per cent & $\mathbf{n}$ & Per cent & & \\
\hline 2004 & 109 & 2.4 & 3283 & 72.3 & 1149 & 25.3 & 4539 & 4539 \\
\hline 2005 & 542 & 2.3 & 16709 & 70.9 & 6311 & 26.8 & 23562 & 23565 \\
\hline 2006 & 585 & 2.3 & 16625 & 66.8 & 7687 & 30.9 & 24897 & 24898 \\
\hline 2007 & 513 & 2.4 & 14303 & 66.2 & 6778 & 31.4 & 21594 & 21375 \\
\hline 2008 & 576 & 2.4 & 14756 & 60.9 & 8899 & 36.7 & 24231 & 24229 \\
\hline 2009 & 621 & 2.6 & 15299 & 62.9 & 8406 & 34.6 & 24326 & 24324 \\
\hline Total & 2944 & 2.4 & 80975 & 65.8 & 39230 & 31.9 & 123149 & 122930 \\
\hline
\end{tabular}


Table 3 Number and proportion of individuals with at least one event (outpatient visit, inpatient episode and colonoscopy) during the first 2 years following randomisation by arm, screening result and type of resource use, in the Finnish colorectal cancer screening programme

\begin{tabular}{|c|c|c|c|c|c|c|}
\hline \multirow[b]{2}{*}{ Event } & \multicolumn{3}{|l|}{ Screening } & \multirow[b]{2}{*}{ Total } & \multirow[b]{2}{*}{ Control } & \multirow[b]{2}{*}{ p Value } \\
\hline & Positive test result & Negative test result & Non-attender & & & \\
\hline Number of individuals & 2944 & 80975 & 39230 & 123149 & 122930 & \\
\hline \multicolumn{7}{|l|}{ Outpatient visits* } \\
\hline $\mathrm{N}$ & 764 & 5705 & 3190 & 9659 & 9136 & $<0.001$ \\
\hline Per cent & 26.0 & 7.0 & 8.1 & 7.8 & 7.4 & \\
\hline \multicolumn{7}{|l|}{ Inpatient episodes* } \\
\hline $\mathrm{N}$ & 243 & 2690 & 1911 & 4844 & 4712 & $<0.001$ \\
\hline Per cent & 8.3 & 3.3 & 4.9 & 3.9 & 3.8 & \\
\hline \multicolumn{7}{|l|}{ Colonoscopies } \\
\hline $\mathrm{N}$ & 339 & 942 & 593 & 1874 & 1559 & $<0.001$ \\
\hline Per cent & 11.5 & 1.2 & 1.5 & 1.5 & 1.3 & \\
\hline
\end{tabular}

people more in the screening group than in the control group with at least one gastrointestinal-related outpatient visit. The corresponding figures for people with at least one inpatient episode or hospital-based colonoscopy were 132 and 315, respectively. The people in the screening group were more likely to undergo more colonoscopies per person than those in the control group (figure 1).

A positive FOBT result increased the probability of using hospital resources. After a positive test result, a quarter of the people had at least one outpatient visit, while $93 \%$ of those with a negative test result had no outpatient visits at all. Also, the probability of undergoing colonoscopy while in hospital was 9.6 times higher in those with a positive test result compared to those with a negative test result. Furthermore, those who were invited to screening but did not attend were more likely to use hospital resources for gastrointestinal reasons than those with a negative FOBT result (table 3).

On average, $2.4 \%$ of the screening population had only one outpatient visit and $5.5 \%$ had two visits or

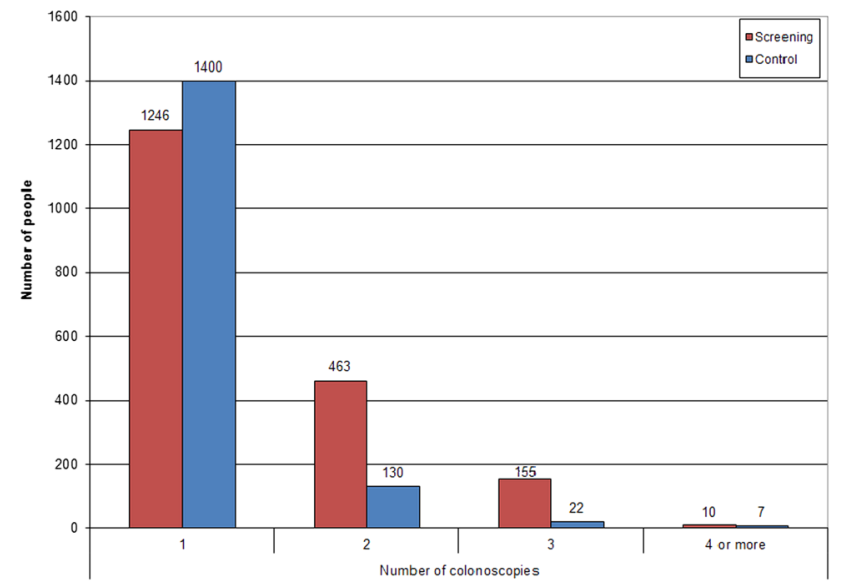

Figure 1 Number of colonoscopies per individual in the Finnish colorectal cancer screening trial in 2004-2010 by arm. more. The corresponding numbers for the control arm were $3.9 \%$ and $3.5 \%$, respectively. Maximum number of visits per person was 86 in the screening group and 141 in the control group.

The cumulative number of outpatient visits, inpatient episodes and hospital colonoscopies over the whole study period is consistently higher in the screening arm than in the control arm (table 4). The difference between the arms was largest in the number of hospital colonoscopies: there were 53\% more colonoscopies performed per individual in the screening group than in the control group. For the outpatient visits and inpatient episodes, the number of events was $18 \%$ and $17 \%$ higher, respectively, in the screening group compared to the control group.

\section{DISCUSSION}

According to this study, the vast majority of the study population, that is, 60-69-year-old Finnish men and women, had not used hospital resources at all for any gastrointestinal-related reasons. Slightly more people in the screening group than in the control group had at least one hospital-based outpatient visit $(7.8 \%$ vs $7.4 \%$ ) or inpatient episode (3.9\% vs $3.8 \%)$. In total, the screening group had 4914 more cumulative outpatient visits and 1357 more inpatient episodes than the control group. The proportions of testpositive people with at least one outpatient visit $(26.0 \%$ vs $7.0 \%)$ or with at least one inpatient episode $(8.3 \%$ vs $3.3 \%)$ were clearly higher than those of people with a negative FOBT result.

The difference in use of hospital resources between the screening and control group is reliably comparable. The setting of the Finnish colorectal cancer screening programme makes it possible to evaluate the feasibility and effectiveness of screening in a randomised, yet realworld healthcare setting. Any possible systematic errors within the Finnish Hospital Discharge registry will be equally present in both groups. 
Table 4 Number of individuals, number of first screening round events (outpatient visits, inpatient episodes and colonoscopies), number of events per individual by arm and type of resource use, during the first 2 years following randomisation in the Finnish colorectal cancer screening programme

\begin{tabular}{|c|c|c|c|c|c|c|c|}
\hline \multirow[b]{2}{*}{ Event } & \multicolumn{2}{|c|}{ Number of individuals } & \multicolumn{2}{|c|}{ Number of events } & \multicolumn{2}{|c|}{$\begin{array}{l}\text { Number of events per } \\
\text { individual }\end{array}$} & \multirow[b]{2}{*}{ p Value } \\
\hline & Screening & Control & Screening & Control & Screening & Control & \\
\hline Outpatient visit* & 123149 & 122930 & 31975 & 27061 & 0.26 & 0.22 & $<0.001$ \\
\hline Inpatient episode* & 123149 & 122930 & 9260 & 7903 & 0.075 & 0.064 & $<0.001$ \\
\hline Colonoscopy & 123149 & 122930 & 2686 & 1756 & 0.022 & 0.014 & $<0.001$ \\
\hline
\end{tabular}

\section{Limitations of the study}

One limitation of the study is the lack of primary care data. Resources used at the primary healthcare level, either by the screening or the control groups, were not registered at FHDR during the study years. Small municipalities with inadequate resources refer patients to hospital for the primary colonoscopy. Other municipalities have their own endoscopy units and their primary colonoscopies are not included in our data. In both cases, if any further examination or treatment (eg, removal of large polyps, suspicious cancer) is necessary, the patient is referred to the secondary healthcare. From earlier work, ${ }^{2}$ we know that $90 \%$ of the test-positives complied to colonoscopy, which means that approximately 2650 primary colonoscopies should be added to the figures of the screening group reported here. However, the lack of data on primary healthcare concerns both, and no comprehensive data are available on possible colonoscopies or other diagnostics at the primary healthcare level in the control group or non-attenders. According to national care guidelines, ${ }^{21}$ the primary investigation for symptomatic patients is endoscopy (not FOBT) and thus controls also have access to primary care endoscopy. The difference in use of primary healthcare services between the two groups can only be speculated, but it is likely that the proportional differences based on FHDR data should indicate any overall differences.

A major concern in FOBT screening and resource use has been the possible increase in the number of diagnostic procedures, mainly colonoscopies, and our study confirms this. In the UK, Price et $a l^{22}$ reported an increase of $21-31 \%$ in the number of hospital colonoscopies due to FOBT screening, but a simultaneous increase was also seen in the demand for symptom-based colonoscopies. In Australia, it has been estimated that a biennial FOBT would result in five times more colonoscopies than the option of no screening. ${ }^{23}$ In our study, a total of 930 more hospital colonoscopies were conducted for the screening group than for the control group, resulting in a 53\% increase in hospital colonoscopies. The proportion of people with at least one colonoscopy was slightly higher in the screening group than in the control group $(1.5 \%$ vs $1.3 \%)$. In particular, patients with a positive FOBT result seemed to increase the probability of hospital resource use, including colonoscopies, compared to those with a negative FOBT or to those who did not attend the screening. This implies that an abnormal finding in the screening results in a number of colonoscopies while without screening, the control group will receive only one diagnostic colonoscopy based on the symptoms, without FOBT.

Based on the present study, it is, however, impossible to say whether the increase is only temporary. For example, Thiis-Evensen $e t a \ell^{24}$ showed that, with a 9-year observation period after a screening colonoscopy, the screening group had $50 \%$ fewer usual-care distal endoscopic examinations than the control group. Furthermore, Seeff $e t a t^{25}$ have argued that if all of the potential endoscopic capacity existing in the USA was used for organised colorectal cancer screening, the unscreened population could be screened within 1 year using the FOBT and colonoscopy for those with a positive test result. For example, follow-up after polypectomy is carried out at more frequent intervals than recommended. In comparison, many published estimates of colonoscopies in cost-effectiveness analyses are reported only for different screening strategies, while the alternative of 'no systematic screening' is often left out or assumed to be zero. ${ }^{11} 1226$

Our screening interval was 2 years. After that, the confounding effect of the second screen is introduced, presuming that the effects of the first and second round are different. In the Finnish CRC screening programme, everyone in the screening group will receive an invitation to screening also during the second round, regardless of the screening result in the first round. The long term evaluation is thus not that straightforward and may include a source of bias.

In conclusion, colorectal cancer screening using the FOBT seems to slightly increase the volume of hospital outpatient visits, inpatient episodes and hospital colonoscopies in Finland.

Acknowledgements The authors would like to acknowledge Jouni Rasilainen (the National Institute for Health and Welfare) for his effort in defining and collecting data.

Contributors NM and MH were involved in study concept and design of the screening programme. All the authors were involved in the study concept and 
design of this resource allocation study. NM and SM were involved in collecting the data. SM, NM, MH and PR were involved in the data and statistical analyses. All the authors read and approved the final version of the manuscript and were involved in the manuscript drafting.

Funding Dr. Malila reports grants from Cancer Society of Finland during the conduct of the study.

Competing interests None.

Ethics approval National Institute for Health and Welfare, Helsinki, Finland (THL/619/5.05.00/2010).

Provenance and peer review Not commissioned; externally peer reviewed.

Data sharing statement No additional data are available.

Open Access This is an Open Access article distributed in accordance with the Creative Commons Attribution Non Commercial (CC BY-NC 4.0) license, which permits others to distribute, remix, adapt, build upon this work noncommercially, and license their derivative works on different terms, provided the original work is properly cited and the use is non-commercial. See: http:// creativecommons.org/licenses/by-nc/4.0/

\section{REFERENCES}

1. Ferlay J, Steliarova-Foucher E, Lortet-Tieulent J, et al. Cancer incidence and mortality patterns in Europe: estimates for 40 countries in 2012. Eur J Cancer 2013;49:1374-403.

2. Malila N, Palva T, Malminiemi O, et al. Coverage and performance of colorectal cancer screening with the feacal occult blood test in Finland. J Med Screen 2011;18:18-23.

3. Finnish Cancer Registry. Cancer statistics, Finland. https://cancer-fi. directo.fi/syoparekisteri/en/statistics/cancer-statistics/koko-maa/ (accessed on Jan 2014).

4. Kronborg O, Jorgensen OD, Fenger $\mathrm{C}$, et al. Randomized study of biennial screening with a faecal occult blood test: results after nine screening rounds. Scand J Gastroenterol 2004;39:846-51.

5. Lindholm E, Brevinge $H$, Haglind $E$. Survival benefit in a randomized clinical trial of faecal occult blood screening for colorectal cancer. $\mathrm{Br}$ J Surg 2008;95:1029-36.

6. Mandel JS, Church TR, Ederer F, et al. Colorectal cancer mortality: effectiveness of biennial screening for fecal occult blood. $J$ Natl Cancer Inst 1999;91:434-7.

7. Scholefield JH, Moss S, Sufi F, et al. Effect of faecal occult blood screening on mortality from colorectal cancer: results from a randomised controlled trial. Gut 2002;50:840-4.

8. Hewitson P, Glasziou PP, Irwig L, et al. Screening for colorectal cancer using the faecal occult blood test, Hemoccult. Cochrane Database of Syst Rev 2007;(1):CD001216.

9. Lansdorp-Vogelaar I, Knudsen AB, Brenner H. Cost-effectiveness of colorectal cancer screening. Epidemiol rev 2011;33:88-100.
10. Tappenden P, Chilcott J, Eggington S, et al. Option appraisal of population-based colorectal cancer screening programmes in England. Gut 2007;56:677-84.

11. Hassan C, Benamouzig R, Spada C, et al. Cost effectiveness and projected national impact of colorectal cancer screening in France. Endoscopy 2011:43:780-9.

12. Heitman SJ, Hilsden RJ, Au F, et al. Colorectal cancer screening for average-risk North Americans: an economic evaluation. PLoS Med 2010;7:e1000370.

13. Macafee DAL, Waller M, Whynes DK, et al. Population screening for colorectal cancer: the implications of an ageing population. $\mathrm{Br} J$ Cancer 2008:99:1991-2000.

14. Telford JJ, Levy AR, Sambrook JC, et al. The cost-effectiveness of screening for colorectal cancer. CMAJ 2010;182:1307-13.

15. van Rossum LGM, van Rijn AF, Verbeek ALM, et al. Colorectal cancer screening comparing no screening, immunochemical and guaiac fecal occult blood tests: a cost-effectiveness analysis. Int $J$ Cancer 2011;128:1908-17.

16. Council of the European Union. Council recommendation of 2 December 2003 on cancer screening (2003/878/EC). L327;16/12/ 2003:0034-0038.

17. Hakama M, Malila N, Dillner J. Randomised health services studies. Int J Cancer 2012;131:2898-902.

18. Malila N, Anttila A, Hakama M. Colorectal cancer screening in Finland: details of the national screening programme implemented in Autumn 2004. J Med Screen 2005;12:28-32.

19. National Institute for Health and Welfare. Official Statistics of Finland. Quality description: Specialized health care. http://www.thl. fi/en_US/web/en/statistics/information/quality_descriptions/ specialised_health_care (accessed in Jan 2014).

20. Sund R. Quality of the Finnish Hospital Discharge Register: a systematic review. Scand J Public Health 2012;40:505-15.

21. Kunnamo I. Colonoscopy and sigmoidoscopy. Evidence-based medicine guidelines; ebm00189. Duodecim 2015. http://www. ebm-guidelines.com/dtk/ebmg/avaa?p_artikkeli=ebm00189 (accessed 3 Nov 2015)

22. Price J, Campbell C, Sells J, et al. Impact of UK Colorectal Cancer Screening Pilot on hospital diagnostic services. Journal of Public Health 2005;27:246-53.

23. O'Leary BA, Olynok JK, Munro Neville A, et al. Cost-effectiveness of colorectal cancer screening: comparison of community-based flexible sigmoidoscopy with fecal occult blood testing and colonoscopy. J Gastroenterol Hepatol 2004;19:38-47.

24. Thiis-Evensen E, Seip B, Vatn MH, et al. Impact of a colonoscopic screening examination for colorectal cancer on later utilization of distal GI endoscopies. Gastrointest Endosc 2006;64:948-54.

25. Seeff LC, Manninen DL, Dong FB, et al. Is there endoscopic capacity to provide Colorectal Cancer screening to the unscreened population in the United States? Gastroenterology 2004;127: 1661-9.

26. Sharp L, Tilson L, Whyte $\mathrm{S}$, et al. Using resource modelling to inform decision making and service planning: the case of colorectal cancer screening in Ireland. BMC Health Serv Res 2013;13:105. 